\title{
Prevalence of Asymptomatic Coronary Artery Stenosis Based on Coronary Computed Tomography Angiography in Adults with Erectile Dysfunction: A Cross-Sectional Study
}

\author{
Ju Young Lee ${ }^{a}$ Sae Rom Lee ${ }^{b, c}$ Sang Yeoup Lee ${ }^{b, c}$ \\ a Department of Family Medicine, Pusan National University School of Medicine, Yangsan, South Korea; \\ ${ }^{b}$ Family Medicine Clinic, Obesity, Metabolism and Nutrition Center and Research Institute of Convergence \\ of Biomedical Science and Technology, Pusan National University Yangsan Hospital, Yangsan, South Korea; \\ 'Department of Medical Education, Pusan National University School of Medicine, Yangsan, South Korea
}

\section{Highlights of the Study}

- Erectile dysfunction was common among men with multiple metabolic risk factors.

- Coronary computed tomography angiography is a noninvasive method for assessing the risk of coronary artery disease.

- Erectile dysfunction is associated with asymptomatic coronary artery stenosis identified using coronary computed tomography angiography.

\section{Keywords}

Coronary artery disease · Computed tomography angiography $\cdot$ Erectile dysfunction

\footnotetext{
Abstract

Objectives: To investigate the prevalence of asymptomatic coronary artery stenosis (CAS) using coronary computed tomography angiography (CCTA) in Korean men with erectile dysfunction (ED). Subjects and Methods: A cross-sectional study was conducted on 108 men who underwent CCTA at a health promotion center in Pusan National University Yangsan Hospital. Each subject who was evaluated for ED using the International Index of Erectile Dysfunction (IIEF) questionnaire did not have a past history or symptoms of coronary artery disease (CAD). We assessed the association between ED and CCTA-based CAS. Results: The overall prevalence of ED was 57.4\%; furthermore, age ( $p=0.001)$ and fasting blood glucose $(p=0.035)$ were the metabolic risk fac-
}

tors that were most significantly associated with the presence of ED. The overall frequency of CAS was $31.5 \%$, and ED $(p=0.022)$, age $(p<0.001)$, fasting blood glucose $(p=0.021)$, and total cholesterol/high-density lipoprotein cholesterol ( $p=0.029$ ) were significantly associated with the presence of CAS. The prevalence of CAS was 40.3 and $19.6 \%$ in the ED and non-ED groups, respectively. Men with ED were 2.778 times more likely to present with CAS than those without ED (OR 2.778, 95\% Cl 1.143-6.749, $p=0.024)$; however multivariate logistic regression analysis, while controlling for age, total cholesterol/high-density lipoprotein cholesterol, and fasting blood glucose, suggested the absence of a significant association between ED and CCTA-based CAS. Conclusion: This study shows that CCTA-based CAS is a common phenomenon in men who have ED. Furthermore, ED patients without cardiac symptoms need to be investigated for the possibility of hidden CAD.

(C) 2020 The Author(s)

Published by S. Karger AG, Basel karger@karger.com www.karger.com/mpp

Karger $\stackrel{\text { ' }}{5}$

GOPEN ACCESS
(C) 2020 The Author(s)

Published by S. Karger AG, Basel

This is an Open Access article licensed under the Creative Commons Attribution-NonCommercial-4.0 International License (CC BY-NC) (http://www.karger.com/Services/OpenAccessLicense), applicable to the online version of the article only. Usage and distribution for commercial purposes requires written permission.
Sang Yeoup Lee

Family Medicine Clinic

Pusan National University Yangsan Hospital

Beomeo-ri Mulgeum-eup, Yangsan 50612 (South Korea)

saylee@pnu.edu 


\section{Introduction}

Erectile dysfunction (ED) is a relatively common condition [1]. Recently, vascular abnormalities, such as cardiovascular risk factors, have been considered as the main causes of ED along with lifestyle factors including smoking and drinking [2]. Most patients with ED have at least one risk factor associated with cardiovascular diseases, including hypertension, diabetes, hyperlipidemia, and obesity [3-6]. In a Korean study of patients with coronary artery disease (CAD) who presented with chest pain, erectile function had considerably reduced due to an increase in the number of affected coronary arteries [7]. Furthermore, despite the absence of clinical cardiovascular diseases, patients with ED may demonstrate vascular dilatation. A previous study reported that ED prevalence was higher in the presence of chronic coronary syndrome than acute coronary syndrome, possibly due to the involvement of a greater number of vessels. Furthermore, ED seemed to appear prior to CAD detection in cases of chronic coronary syndrome [8]. Therefore, ED may be an important predictor of subclinical CAD [9]. However, only a small number of studies have attempted to determine the relationship between ED and asymptomatic CAD, particularly in Korean men. Therefore, we investigated the prevalence of asymptomatic coronary artery stenosis (CAS) using coronary computed tomography angiography (CCTA) in Korean men with ED and without cardiovascular symptoms.

\section{Subjects and Methods}

\section{Study Subjects}

This cross-sectional study was conducted by a review of records in the Center for Health Promotion, a University Hospital. Initially, data were collected from subjects (Korean men; age $\geq 18$ years) who underwent a self-paid comprehensive health checkup, including CCTA, between January 2014 and January 2015. Finally, a total of 108 subjects were included in this analysis. Patients who presented with a history of cardiovascular disease and stroke, and those who did not respond to the International Index of Erectile Dysfunction (IIEF) questionnaire or undergo CCTA were excluded. The questionnaire was used to investigate smoking habits, current or past history of hypertension, diabetes, hyperlipidemia, cardiovascular disease, and stroke, among other parameters.

\section{Data Collection and Measurements}

Height and weight were measured with an electronic body meter HM-300 (Fanics Co., Ltd., Busan, South Korea) with a light-weight gown and a height of $0.1 \mathrm{~cm}$ and a body weight of $0.1 \mathrm{~kg}$. Body mass index $\left(\mathrm{kg} / \mathrm{m}^{2}\right)$ was calculated according to the measured height and weight. Blood pressure was recorded using a sphygmomanometer (BP-203 RV II; Colin Corp., Aichi, Japan). Waist circumference was measured at the narrowest point between the lower borders of the rib cage and the uppermost borders of the iliac crest; the patients were instructed to exhale normally to conform to the guidelines of the World Health Organization, and the measurements were then recorded up to 0.1 $\mathrm{cm}$. The subjects' blood was collected after fasting for more than 8 h. Total cholesterol (TC), low-density lipoprotein (LDL) cholesterol, high-density lipoprotein (HDL) cholesterol, triglyceride, fasting glucose, and insulin concentrations were measured. The subjects' age was divided into 4 groups according to percentile $(\mathrm{Q} 1 \leq 47,48 \leq \mathrm{Q} 2 \leq 53,54 \leq \mathrm{Q} 3 \leq 57$, and $58 \leq \mathrm{Q} 4$ years of age).

\section{The Atherogenic Index}

TC/HDL ratio, known as the atherogenic index, was considered as a more sensitive and specific index of CAD risk than the isolated parameters. The optimal ratio was $\leq 3.5$ [10].

\section{Insulin Resistance}

The HOMA-IR, which is also known as the insulin resistance index, was calculated as (homeostasis model assessment index-insulin resistance $=$ fasting insulin $[\mathrm{mU} / \mathrm{mL}] \times$ fasting glucose $[\mathrm{mg} /$ $\mathrm{dL}] / 405$ ) [11], and the reference value $\geq 2.34$ associated with the metabolic syndrome was considered to be indicative of insulin resistance [12].

\section{Definition of Metabolic Syndrome}

The abdominal obesity item was applied to men with waist circumference $\geq 90 \mathrm{~cm}$, according to waist circumference criteria of Koreans [13]. Metabolic syndrome was defined according to the criteria of the NCEP/ATP III to include individuals demonstrating any 3 or more parameters among the following 5 components: [14] waist circumference $\geq 90 \mathrm{~cm}$ (men); blood pressure $\geq 130 / 85$ $\mathrm{mmHg}$ or anti-hypertensive medication; fasting blood glucose $\geq 100 \mathrm{mg} / \mathrm{dL}$ or hypoglycemic agents; triglycerides $\geq 150 \mathrm{mg} / \mathrm{dL}$ or lipid-lowering medication; and HDL cholesterol $<40 \mathrm{mg} / \mathrm{dL}$ (men) or lipid-lowering medication.

\section{Assessment of Erectile Function}

The Korean version of IIEF was rated as $1-5$ points for each of the 6 items indicating erection dysfunction. According to the total score, 5-7 points were rated as severe $\mathrm{ED}, 8-11$ as moderate, $12-16$ mild to moderate, $17-21$ mild, and $22-25$ as normal function. The subjects were divided into 2 groups: normal group and ED groups [15].

\section{Coronary CT Angiography}

CAS was evaluated using a 128-slice CT device (Definition AS+; Siemens Medical Solutions, Forchheim, Germany). Before the imaging, all subjects were instructed to fast for a minimum period of $8 \mathrm{~h}$. Subjects with a heart rate over 70 beats/min were given a single 20-mg dose of propranolol. Seventy milliliters of iopromide (Ultravist 370; BSP, Germany) was administered via the antecubital vein at a rate of $5 \mathrm{~mL} / \mathrm{s}$. Subsequently, the patients were also administered with iopromide mixed with saline in a 4:1 ratio. Plaques were defined as visible structures within or adjacent to the coronary artery lumen, which could be clearly distinguished from the vessel lumen and the surrounding pericardial tissue. In the present study, coronary stenosis was defined as a more than $25 \%$ 
Table 1. Baseline characteristics of the subjects $(n=108)$

\begin{tabular}{lc}
\hline Variables & Value \\
\hline Age, years & $53.0 \pm 8.6$ \\
Smoking status & \\
$\quad$ Smoker & $48(44.9)$ \\
$\quad$ Ex-smoking & $44(40.5)$ \\
$\quad$ Never & $16(14.8)$ \\
Erectile dysfunction & \\
$\quad$ No & $46(42.6)$ \\
$\quad$ Yes & $62(57.4)$ \\
Coronary artery stenosis & \\
$\quad$ No & $74(68.5)$ \\
$\quad$ Yes & $34(31.5)$ \\
Systolic blood pressure, mm Hg & $121.8 \pm 10.9$ \\
Diastolic blood pressure, mm Hg & $80.5 \pm 5.9$ \\
Body mass index, kg/m ${ }^{2}$ & $25.0 \pm 3.0$ \\
Waist circumference, cm & $89.8 \pm 9.4$ \\
Fasting glucose, mg/dL & $101.7 \pm 34.7$ \\
Triglyceride, mg/dL & $122.5(49.0-679.0)$ \\
HDL cholesterol, mg/dL & $49.6 \pm 11.7$ \\
Total cholesterol, mg/dL & $217.1 \pm 44.6$ \\
LDL cholesterol, mg/dL & $139.2 \pm 38.4$ \\
Insulin, $\mu$ IU/mL & $4.7(1.2-60.5)$ \\
Total cholesterol/HDL cholesterol ratio & $4.5 \pm 1.1$ \\
HOMA-IR & $1.0(0.2-26.1)$ \\
\hline
\end{tabular}

Data are presented as mean $\pm \mathrm{SD}$, median (range), or $n(\%)$.

luminal reduction in the most severe cases of stenosis in the calcified segments of the coronary arteries for the earlier stages of cardiovascular disease.

\section{Statistical Analysis}

The subjects were classified into 2 groups according to the presence of ED and CCTA-based CAS. The $\chi^{2}$ test was used to evaluate the difference of the factors between them. Multivariate logistic regression analysis was used to determine the odds ratio and $95 \%$ CI for CCTA-based CAS according to age, fasting blood glucose, $\mathrm{TC} / \mathrm{HDL}$ ratio, and presence of $\mathrm{ED}$. A $p$ value of $<0.05$ was considered statistically significant. SPSS version 22.0 (SPSS Statistics for Windows version 22.0; IBM Corp., Armonk, NY, USA) was employed for the analysis.

\section{Results}

\section{General Characteristics of Subjects}

The subjects comprised 108 men with an average age of $53.5(28-78)$ years. Sixty-two men (57.4\%) had ED and $34(31.5 \%)$ presented with CAS on CCTA. Smoking status was assessed and resulted in smoking, nonsmoking, and smoking cessation in 48 (44.9\%), 16 (14.8\%) and 44 (40.5\%) subjects, respectively (Table 1 ).

Coronary Artery Stenosis and Erectile Dysfunction
Table 2. Comparison of risk factors between subjects without and with erectile dysfunction (ED)

\begin{tabular}{|c|c|c|c|}
\hline Parameters & $\begin{array}{l}\text { Subjects } \\
\text { without ED }\end{array}$ & $\begin{array}{l}\text { Subjects } \\
\text { with ED }\end{array}$ & $\begin{array}{l}p \\
\text { value* }\end{array}$ \\
\hline Subjects & $46(42.6)$ & $62(57.4)$ & \\
\hline Age & & & 0.001 \\
\hline $\mathrm{Q} 1 \leq 47$ years & $15(65.2)$ & $8(34.8)$ & \\
\hline $48 \leq \mathrm{Q} 2 \leq 53$ years & $17(50.0)$ & $17(50.0)$ & \\
\hline $54 \leq \mathrm{Q} 3 \leq 57$ years & $8(38.1)$ & $13(61.9)$ & \\
\hline $58 \leq \mathrm{Q} 4$ years & $6(20.0)$ & $24(80.0)$ & \\
\hline Smoking & & & 0.130 \\
\hline Never & $4(8.7)$ & $12(19.4)$ & \\
\hline Smoker & $25(54.3)$ & $23(37.1)$ & \\
\hline Ex-smoker & $17(37.0)$ & $27(43.5)$ & \\
\hline \multicolumn{4}{|l|}{ Metabolic factors } \\
\hline $\mathrm{BP} \geq 130 / 85 \mathrm{~mm} \mathrm{Hg}$ or drugs & $28(60.9)$ & $39(62.9)$ & 0.829 \\
\hline $\mathrm{WC} \geq 90 \mathrm{~cm}$ & $27(58.7)$ & $30(48.4)$ & 0.289 \\
\hline FBG $\geq 100 \mathrm{mg} / \mathrm{dL}$ or drugs & $13(28.3)$ & $30(48.4)$ & 0.035 \\
\hline $\mathrm{TG} \geq 150 \mathrm{mg} / \mathrm{dL}$ or drugs & $22(47.8)$ & $23(37.1)$ & 0.263 \\
\hline HDL-C $<40 \mathrm{mg} / \mathrm{dL}$ or drugs & $13(28.3)$ & $18(29.0)$ & 0.930 \\
\hline Metabolic syndrome & $21(45.7)$ & $28(45.2)$ & 0.960 \\
\hline TC/HDL-C > 3.5 & $41(89.1)$ & $48(77.4)$ & 0.114 \\
\hline HOMA-IR $\geq 2.34$ & $5(10.9)$ & $10(16.1)$ & 0.434 \\
\hline
\end{tabular}

Data are presented as $n(\%)$. BP, blood pressure; WC, waist circumference; FBG, fasting blood glucose; TG, triglyceride; HDL-C, high-density lipoprotein cholesterol; HOMA-IR, homeostasis model assessment index-insulin resistance. ${ }^{\star} \mathrm{By} \chi^{2}$ test or linear by linear association.

\section{Differences in Metabolic Parameters between the ED Group and the Non-ED Group}

Dividing the age of the subjects into quartiles, there was a statistically significant increase in the prevalence of ED with age $(p=0.001)$. There was no statistically significant difference in smoking and metabolic syndrome between the 2 groups $(p=0.960)$. Analysis of the metabolic risk factors revealed that the fasting glucose and diabetic groups demonstrated a statistically significant association ( $p=0.035)$. There was no difference in the prevalence of high HOMA-IR $(\geq 2.34)$ and high TC/HDL ratio ( $>3.5$ ) between the 2 groups (Table 2 ).

\section{Metabolic Parameters between the CCTA-Based CAS \\ Group and the Non-CAS Group}

Dividing the age of the subjects into quartiles, the probability of showing CCTA-based CAS was significantly increased with age $(p<0.001)$. The prevalence of CCTA-based CAS was significantly higher in the ED group than in the non-ED group ( $p=0.022)$. In addition, the prevalence of CCTA-based CAS tended to signifi- 
Table 3. Prevalence of coronary artery stenosis according to severity of erectile dysfunction

\begin{tabular}{lrrrrr}
\hline $\begin{array}{l}\text { Coronary } \\
\text { artery } \\
\text { stenosis }\end{array}$ & \multicolumn{4}{l}{ Severity of erectile dysfunction } \\
\cline { 2 - 6 } & none & \multicolumn{1}{l}{ mild } & $\begin{array}{l}\text { mild to } \\
\text { moderate }\end{array}$ & moderate & severe \\
\hline No $(n=74)$ & $37(80.4)$ & $15(62.5)$ & $8(72.7)$ & $4(66.7)$ & $10(47.6)$ \\
Yes $(n=34)$ & $9(19.6)$ & $9(37.5)$ & $3(27.3)$ & $2(33.3)$ & $11(52.4)$ \\
\hline
\end{tabular}

Data are presented as $n(\%) . p=0.014$, by linear by linear association.

cantly increase with the severity of $\operatorname{ED}(p=0.014$; Tables $3,4)$. The presence of metabolic syndrome was not statistically significant between the 2 groups. Analysis based on the metabolic risk factors revealed that CCTAbased CAS was significantly higher in the high fasting glucose or diabetic subgroup $(p=0.021)$. A higher HOMA-IR was not significantly different between the CCTA-based CAS group and the non-CAS groups $(p=$ 0.444 ); however, a higher TC/HDL ratio demonstrated a significant difference between the 2 groups ( $p=0.029$; Table 4).

\section{The Odds Ratio of CCTA-Based CAS according to ED} and Metabolic Risk Factors

In ED alone, the odds ratio of CCTA-based CAS was 2.778 times higher in the ED group ( $\mathrm{OR}=2.778,95 \% \mathrm{CI}$ $1.143-6.749, p=0.024)$. However, multivariate logistic regression analysis showed that age, ED, a higher TC/ HDL ratio, and a higher fasting blood glucose affected CCTA-based CAS; furthermore, the odds ratio of CCTAbased CAS was not statistically significant except for age. In the fourth quartile of age, the Q2 group ( $\mathrm{OR}=2.173$, $95 \%$ CI $0.389-12.153, p=0.377$ ) had no statistical significance compared with the Q1 group, but the Q3 group $(\mathrm{OR}=9.045,95 \%$ CI $1.617-50.598, p=0.012)$ and the $\mathrm{Q} 4$ group $(\mathrm{OR}=5.576,95 \% \mathrm{CI} 1.032-30.115, p=0.046) \mathrm{dem}-$ onstrated statistically significant higher odds ratios of CCTA-based CAS (Table 5).

\section{Discussion}

In this study, we investigated the prevalence of asymptomatic CAS based on CCTA and the relationship between ED and CAS in asymptomatic Korean men with ED. CCTA is a noninvasive method for quantify-
Table 4. Comparison of risk factors between subjects without and with coronary artery stenosis (CAS)

\begin{tabular}{|c|c|c|c|}
\hline Parameters & $\begin{array}{l}\text { Subjects } \\
\text { without CAS }\end{array}$ & $\begin{array}{l}\text { Subjects } \\
\text { with CAS }\end{array}$ & $p$ value \\
\hline Subjects & $74(68.5)$ & $34(31.5)$ & \multirow{6}{*}{0.000} \\
\hline \multicolumn{3}{|l|}{ Age } & \\
\hline $\mathrm{Q} 1 \leq 47$ years & $21(91.3)$ & $2(8.7)$ & \\
\hline $48 \leq \mathrm{Q} 2 \leq 53$ years & $27(79.4)$ & $7(20.6)$ & \\
\hline $54 \leq \mathrm{Q} 3 \leq 57$ years & $10(47.6)$ & $11(52.4)$ & \\
\hline $58 \leq \mathrm{Q} 4$ years & $16(53.3)$ & $14(46.7)$ & \\
\hline \multicolumn{3}{|l|}{ Smoking } & \multirow[t]{4}{*}{0.917} \\
\hline Never & $11(14.9)$ & $5(14.7)$ & \\
\hline Smoker & $35(47.3)$ & $13(38.2)$ & \\
\hline Ex-smoker & $28(37.8)$ & $16(47.1)$ & \\
\hline \multicolumn{3}{|l|}{ Erectile dysfunction } & \multirow[t]{3}{*}{0.022} \\
\hline No & $37(50.0)$ & $9(26.5)$ & \\
\hline Yes & $37(50.0)$ & $25(73.5)$ & \\
\hline \multicolumn{4}{|l|}{ Metabolic factors } \\
\hline $\mathrm{BP} \geq 130 / 85 \mathrm{~mm} \mathrm{Hg}$ or drug & $44(59.5)$ & $23(67.6)$ & 0.415 \\
\hline $\mathrm{WC} \geq 90 \mathrm{~cm}$ & $35(47.3)$ & $22(64.7)$ & 0.092 \\
\hline $\mathrm{FBG} \geq 100 \mathrm{mg} / \mathrm{dL}$ or drug & $24(32.4)$ & $19(55.9)$ & 0.021 \\
\hline $\mathrm{TG} \geq 150 \mathrm{mg} / \mathrm{dL}$ or drug & $34(45.9)$ & $11(32.4)$ & 0.183 \\
\hline HDL-C $<40 \mathrm{mg} / \mathrm{dL}$ or drug & $21(28.4)$ & $10(29.4)$ & 0.912 \\
\hline Metabolic syndrome & $32(43.2)$ & $17(50.5)$ & 0.521 \\
\hline TC/HDL-C >3.5 & $65(87.8)$ & $24(70.6)$ & 0.029 \\
\hline HOMA-IR $\geq 2.34$ & $9(12.2)$ & $6(17.6)$ & 0.444 \\
\hline
\end{tabular}

Data are presented as $n(\%)$. BP, blood pressure; WC, waist circumference; FBG, fasting blood glucose; TG, triglyceride; HDL-C, high-density lipoprotein cholesterol; HOMA-IR, homeostasis model assessment index-insulin resistance. ${ }^{*}$ By $\chi^{2}$ test or linear by linear association.

ing atherosclerotic plaque and assessing the risk of $\mathrm{CAD}$, as well as for differentiating the presence or absence of significant stenosis of the coronary artery [16]. A previous study showed that the overall sensitivity and specificity of 128 -slice CCTA was $100 \%$ (95\% CI $39.8-$ $100 \%$ ) and $91.3 \%$ (95\% CI 79.2-97.6\%), respectively [17].

The prevalence of CAS was 40.3 and $19.6 \%$ in the ED and non-ED groups, respectively. On the other hand, the association between IIEF-assessed ED and CAS detected by CCTA was abolished after adjustments. However, it does not negate the importance of our study findings; rather, it suggests that $\mathrm{ED}$ acts in combination with several factors including aging and atherosclerosis, resulting in CAS. It is imperative to consider that ED patients who do not demonstrate symptoms of cardiovascular diseases may have clinically significant diseases such as asymptomatic CAD. These results are similar to those of a previous study which reported that ED had a stronger association with age than other environmental or chronic risk factors including smoking or drinking 
Table 5. Multivariate logistic regression of erectile dysfunction and the accompanying metabolic risk factors with coronary artery stenosis

\begin{tabular}{llll}
\hline Model & \multicolumn{2}{l}{$\begin{array}{l}\text { Coronary artery } \\
\text { stenosis }\end{array}$} & $\begin{array}{l}p \\
\text { value }\end{array}$ \\
\cline { 2 - 3 } & OR & \\
& $25 \% \mathrm{CI}$ & \\
\hline $\begin{array}{l}\text { Erectile dysfunction } \\
\text { Multiple logistic regression }\end{array}$ & & $1.143-6.749$ & 0.024 \\
Age & & & \\
$\quad$ Q1 $\leq 47$ years & & & \\
$\quad 48 \leq \mathrm{Q} 2 \leq 53$ years & 2.173 & $0.389-12.153$ & 0.377 \\
$\quad 54 \leq \mathrm{Q} 3 \leq 57$ years & 9.045 & $1.617-50.598$ & 0.012 \\
$58 \leq \mathrm{Q} 4$ years & 5.576 & $1.032-30.115$ & 0.046 \\
$\quad$ Erectile dysfunction & 1.660 & $0.610-4.518$ & 0.321 \\
TC/HDL-C & 0.447 & $0.143-1.397$ & 0.166 \\
Fasting blood glucose & 2.145 & $0.855-5.379$ & 0.104 \\
\hline
\end{tabular}

OR, odds ratio; CI, confidence interval; TC, total cholesterol; HDL-C, high-density lipoprotein cholesterol.

[18]. Another study suggested that sexual dysfunction is more common in older patients; however, this association between sexual dysfunction and age was stronger in the presence of chronic diseases [19]. In patients with $\mathrm{ED}$ and traditional cardiovascular risk factors, our findings suggested that if CCTA is performed routinely, 4 out of 10 Korean patients with ED will present with asymptomatic CAD.

ED is a very common disease that affects $30-50 \%$ of middle-aged men and is a serious social problem that causes reduced self-esteem, psychological frustration, poor quality of life, and stress $[1,20]$. Previous studies reported that ED is often accompanied by comorbid conditions such as hypertension, hypercholesterolemia, and diabetes [21]. Conversely, ED incidence was 2 times higher in men with metabolic syndrome than those in the control group, and the risk of ED increases with increasing risk factors of metabolic syndrome [22]. It is also reported that $20-85 \%$ of diabetic patients have $\mathrm{ED}$, and a longer the duration of diabetes was associated with a poorer control of blood glucose, suggesting a higher frequency of ED [23]. Binmoammar et al. [24] reported that ED is an important predictor of asymptomatic CAD in type 2 diabetic patients. In addition, Wang et al. [25] reported that hypertension was associated with increased risk of ED (summary OR $=1.58$, $95 \%$ CI $1.35-1.86, p<0.001$ ). It is now recognized that $\mathrm{ED}$ is not a single disease but part of a syndrome that is related to other vascular diseases, especially cardiovascular disease [26]. Furthermore, men with coronary heart disease are less likely to demonstrate ED (47.4 vs. $38.1 \%$, OR 1.46 , 95\% CI 1.10-1.93) than those without [27]. When severity of CCTA-based CAS was compared with erectile function through questionnaires in CAD patients with chest pain, the erectile function reduced significantly with an increase in the number of affected coronary arteries [28]. This tendency was observed in this study as well. The association between ED and CAD is presumed to be due to the initial endothelial dysfunction and peripheral occlusive vessel changes in the common pathophysiologic mechanism [2, 25, 29]. Alternatively, ED is considered to be a precursor symptom observed before the manifestation of cardiovascular disease [30]. Atherosclerosis, which is a systemic vascular disease, affects several blood vessels simultaneously, but this effect does not appear to be a clinical consequence. Because the diameter of the penile artery (1-2 $\mathrm{mm}$ ) is smaller than the diameter of the coronary artery (3-4 $\mathrm{mm})$ or the carotid artery (5-7 $\mathrm{mm})$, clinical symptoms first appear as erectile function, followed by ischemic heart symptoms, followed by cerebrovascular and peripheral vascular symptoms [26, 28]. A previous study demonstrated that a considerable proportion of patients with nonpsychogenic and nonhormonal ED had angiographically proven asymptomatic CAD [31]. The noninvasive nature of CCTA as a useful method for assessing the risk of CAD is a strength of this study. The very high prevalence of asymptomatic CAD in Korean men with ED may suggest the need for a more aggressive approach for the identification of asymptomatic CAD in patients with ED.

The present study has some limitations. First, it had a retrospective cross-sectional study design, and was based on apparently healthy people who underwent a general health checkup. Therefore, the results may be influenced by selection biases or unobserved confounders. Second, the subjects who participated in the health checkup survey had a more favorable lifestyle, such as less smoking and alcohol consumption, compared to those who did not participate. Therefore, these findings may not be readily generalized to the whole population. Third, our participants were all Koreans. Therefore, generalizing the findings of this study to a large population should be done carefully. Despite the limitations of the present study, it was the first study of the association of CCTA-based CAS with ED in Korean men without a history or symptoms of cardiovascular disease. 


\section{Conclusion}

IIEF-assessed ED was associated with asymptomatic cardiovascular disease as detected by CCTA. Therefore, the possibility of hidden CAD will need to be investigated, although there are no chest symptoms in patients with ED. However, there is a need for a more large-scale research study to reconfirm this result.

\section{Statement of Ethics}

As this study used pre-existing, de-identified data, it was exempt from Institutional Review Board approval (IRB No. 05-2015129). The procedures were in accordance with the Institutional Review Board at Pusan National University Yangsan Hospital and the Helsinki Declaration.

\section{Conflict of Interest Statement}

There are no conflicts of interest.

\section{Funding Sources}

There are no funding sources to declare.

\section{Author Contributions}

J.Y.L. and S.Y.L. conceived and designed the study, collected the data, and wrote the paper. S.R.L. collected and analyzed the data. All authors discussed the results and contributed to the final manuscript.

\section{References}

1 Shamloul R, Ghanem H. Erectile dysfunction. Lancet. 2013 Jan;381(9861):153-65.

2 Gerber RE, Vita JA, Ganz P, Wager CG, Araujo AB, Rosen RC, et al. Association of peripheral microvascular dysfunction and erectile dysfunction. J Urol. 2015 Feb;193(2):612-7.

3 Baumann F, Hehli D, Makaloski V, Schumacher M, Schönhofen H, Diehm N. Erectile dysfunction - overview from a cardiovascular perspective. Vasa. 2017 Aug;46(5):347-53.

4 Chaudhary RK, Shamsi BH, Chen HM, Tan $\mathrm{T}$, Tang KF, Xing JP. Risk factors for erectile dysfunction in patients with cardiovascular disease. J Int Med Res. 2016 Jun;44(3):718-27.

5 García-Cruz E, Leibar-Tamayo A, Romero J, Piqueras M, Luque P, Cardeñosa O, et al. Metabolic syndrome in men with low testosterone levels: relationship with cardiovascular risk factors and comorbidities and with erectile dysfunction. J Sex Med. 2013 Oct;10(10): 2529-38.

6 Uddin SM, Mirbolouk M, Dardari Z, Feldman DI, Cainzos-Achirica M, DeFilippis AP, et al. Erectile dysfunction as an independent predictor of future cardiovascular events. Circulation. 2018 Jul;138(5):540-2.

7 Kim HW, Park WJ, Choi YS, Cho SY. The correlation between erectile dysfunction and the severity of coronary artery involvement in patients with coronary artery disease. Korean J Urol. 2007;48(1):94-102.

8 Montorsi P, Ravagnani PM, Galli S, Rotatori F, Veglia F, Briganti A, et al. Association between erectile dysfunction and coronary artery disease. Role of coronary clinical presentation and extent of coronary vessels involvement: the COBRA trial. Eur Heart J. 2006 Nov;27(22):2632-9.

9 Feldman DI, Cainzos-Achirica M, Billups KL, DeFilippis AP, Chitaley K, Greenland P, et al. Subclinical vascular disease and subsequent erectile dysfunction: The Multiethnic Study of Atherosclerosis (MESA). Clin Cardiol. 2016 May;39(5):291-8.

10 Millán J, Pintó X, Muñoz A, Zúñiga M, Rubiés-Prat J, Pallardo LF, et al. Lipoprotein ratios: physiological significance and clinical usefulness in cardiovascular prevention. Vasc Health Risk Manag. 2009;5:757-65.

11 Matthews DR, Hosker JP, Rudenski AS, Naylor BA, Treacher DF, Turner RC. Homeostasis model assessment: insulin resistance and beta-cell function from fasting plasma glucose and insulin concentrations in man. Diabetologia. 1985 Jul;28(7):412-9.

12 Yun KJ, Han K, Kim MK, Park YM, Baek KH, Song $\mathrm{KH}$, et al. Insulin resistance distribution and cut-off value in Koreans from the 20082010 Korean National Health and Nutrition Examination Survey. PLoS One. 2016 Apr; 11(4):e0154593.

13 Lee SY, Park HS, Kim DJ, Han JH, Kim SM, Cho GJ, et al. Appropriate waist circumference cutoff points for central obesity in Korean adults. Diabetes Res Clin Pract. 2007 Jan; 75(1):72-80.

14 Grundy SM, Cleeman JI, Daniels SR, Donato KA, Eckel RH, Franklin BA, et al.; American Heart Association; National Heart, Lung, and Blood Institute. Diagnosis and management of the metabolic syndrome: an American Heart Association/National Heart, Lung, and Blood Institute Scientific Statement. Circulation. 2005 Oct;112(17):2735-52.

15 Ahn TY, Park JK, Lee SW, Hong JH, Park NC, Kim JJ, et al. Prevalence and risk factors for erectile dysfunction in Korean men: results of an epidemiological study. J Sex Med. 2007 Sep;4(5):1269-76.

16 Davies MJ, Newton JD. Non-invasive imaging in cardiology for the generalist. Br J Hosp Med (Lond). 2017 Jul;78(7):392-8.
17 Joshi H, Shah R, Prajapati J, Bhangdiya V, Shah J, Kandre Y, et al. Diagnostic accuracy of computed tomography angiography as compared to conventional angiography in patients undergoing noncoronary cardiac surgery. Heart Views. 2016 Jul-Sep;17(3):88-91.

18 Weber MF, Smith DP, O'Connell DL, Patel MI, de Souza PL, Sitas F, et al. Risk factors for erectile dysfunction in a cohort of 108477 Australian men. Med J Aust. 2013 Jul;199(2):107-11.

19 Maiorino MI, Bellastella G, Esposito K. Lifestyle modifications and erectile dysfunction: what can be expected? Asian J Androl. 2015 Jan-Feb;17(1):5-10.

20 Echeverri Tirado LC, Ferrer JE, Herrera AM. Aging and erectile dysfunction. Sex Med Rev. 2016 Jan;4(1):63-73.

21 Sanchez E, Pastuszak AW, Khera M. Erectile dysfunction, metabolic syndrome, and cardiovascular risks: facts and controversies. Transl Androl Urol. 2017 Feb;6(1):28-36.

22 Besiroglu H, Otunctemur A, Ozbek E. The relationship between metabolic syndrome, its components, and erectile dysfunction: a systematic review and a meta-analysis of observational studies. J Sex Med. 2015 Jun;12(6):1309-18.

23 Kouidrat Y, Pizzol D, Cosco T, Thompson T, Carnaghi M, Bertoldo A, et al. High prevalence of erectile dysfunction in diabetes: a systematic review and meta-analysis of 145 studies. Diabet Med. 2017 Sep;34(9):1185-92.

24 Binmoammar TA, Hassounah S, Alsaad S, Rawaf S, Majeed A. The impact of poor glycaemic control on the prevalence of erectile dysfunction in men with type 2 diabetes mellitus: a systematic review. JRSM Open. 2016 Feb;7(3):2054270415622602.

25 Wang XY, Huang W, Zhang Y. Relation between hypertension and erectile dysfunction: a meta-analysisof cross-section studies. Int $\mathrm{J}$ Impot Res. 2018 Jun;30(3):141-6. 
26 Gandaglia G, Briganti A, Jackson G, Kloner RA, Montorsi F, Montorsi P, et al. A systematic review of the association between erectile dysfunction and cardiovascular disease. Eur Urol. 2014 May;65(5):968-78.

27 Steptoe A, Jackson SE, Wardle J. Sexual activity and concerns in people with coronary heart disease from a population-based study. Heart. 2016 Jul;102(14):1095-9.
28 Justo D, Arbel Y, Mulat B, Mashav N, Saar N, Steinvil A, et al. Sexual activity and erectile dysfunction in elderly men with angiographically documented coronary artery disease. Int J Impot Res. 2010 Jan-Feb;22(1):40-4.

29 Peyton CC, Colaco MA, Kovell RC, Kim JH, Terlecki RP. Erectile dysfunction is predictive of endothelial dysfunction in a well visit population. J Urol. 2016 Apr;195(4 Pt 1):1045-50.
30 Banks E, Joshy G, Abhayaratna WP, Kritharides L, Macdonald PS, Korda RJ, et al. Erectile dysfunction severity as a risk marker for cardiovascular disease hospitalisation and allcause mortality: a prospective cohort study. PLoS Med. 2013;10(1):e1001372.

31 Vlachopoulos C, Rokkas K, Ioakeimidis N, Aggeli C, Michaelides A, Roussakis G, et al. Prevalence of asymptomatic coronary artery disease in men with vasculogenic erectile dysfunction: a prospective angiographic study. Eur Urol. 2005 Dec;48(6):996-1002. 